\title{
A study of Vishnukundin coins
}

\author{
M VIJAYAKUMAR*, M C GANORKAR, V PANDIT RAO and \\ P GAYATHRI \\ *Defence Metallurgical Research Laboratory, Kanchanbagh, Hyderabad 500 258, India \\ Division of Scientific Studies, Birla Archaeological and Cultural Research Institute, Hyderabad \\ 500 036. India \\ MS received 27 February 1987
}

\begin{abstract}
Three types of Vishnukundin coins belonging to Andhra region were subjected to chemical and microstructural studies. The source of the ores used, the nature of the alloy and the techniques employed have been inferred from the data obtained. Trace elemental data have shown that the coins were made of unrefined metal which was also confirmed by electron microprobe results.
\end{abstract}

Keywords. Coin; Vishnukundin; chemical analysis; microstructural study.

\section{Introduction}

Vishnukundins were a major dynasty since the fall of the Satavahanas which enjoyed imperial status over the entire Andhra region including Kalinga (Orissa) and some parts of Maharastra. The period of Vishnukundin rule was about 140 years from 475 A.D. During their rule, they have issued a number of coins some of which have been studied (Rama Rao 1963; Hegde 1975).

The Birla Archaeological and Cultural Research Institute (BACRI) obtained about 500 coins belonging to the Vishnukundin period from a local antique dealer. The Andhra Pradesh State Department of Archaeology and Museums (SDAM) also has a number of Vishnukundin coins obtained through excavation, exploration and treasure troves from various parts of Andhra Pradesh. Compositional and microstructural study of these coins can provide a clue to the materials used and the distinctive techniques employed during the period in making the coins. Viewing with this hindsight, it is also possible to gauge the technological competence and expertise available in the various regions. We have chosen the following three types of Vishnukundin coins for a detailed investigation: (a) BACRI coins said to be obtained from the Nalgonda area. though details are not known clearly. (b) Kesaragutta coins obtained from the Kesaragutta excavations, Ranga Reddy district, AP by the State Department of Archaeology and Museums, and (c) Tangadupalli coins obtained from a treasure trove at Tangadupalli Village, Nellimarla taluka, Vizianagaram District, AP again by the State Department of Archaeology and Museums.

All the three types of coins were round in shape and showed a lion in a circle on the obverse and a sankha flanked by lampstands on either side inside a rayed circle on the reverse, which is typical of the designs on the coins of Vishnukundin period (figure 1). BACRI coins had surface cracks and were covered with red and black incrustations. Most of the Kesaragutta and Tangadupalli coins on the other hand were in fairly good condition, and legends and designs could be clearly seen. A few had surface cracks. Greenish and black incrustations were also noticed. 
Reverse

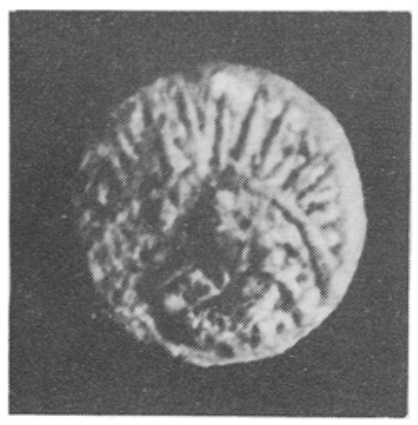

Obverse

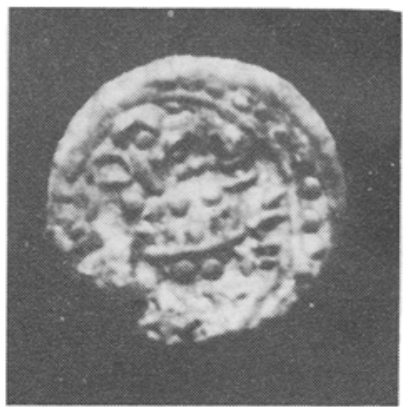

\section{A. BACRI coins}
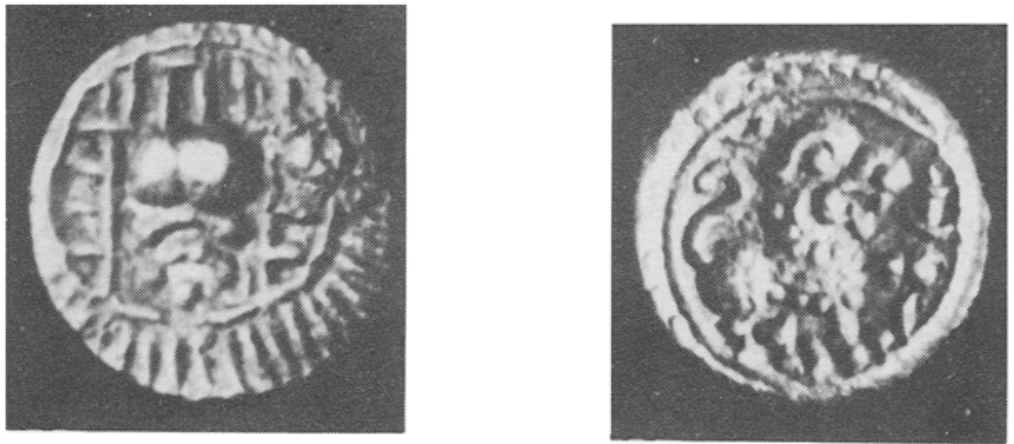

B. Kesaragutta coins
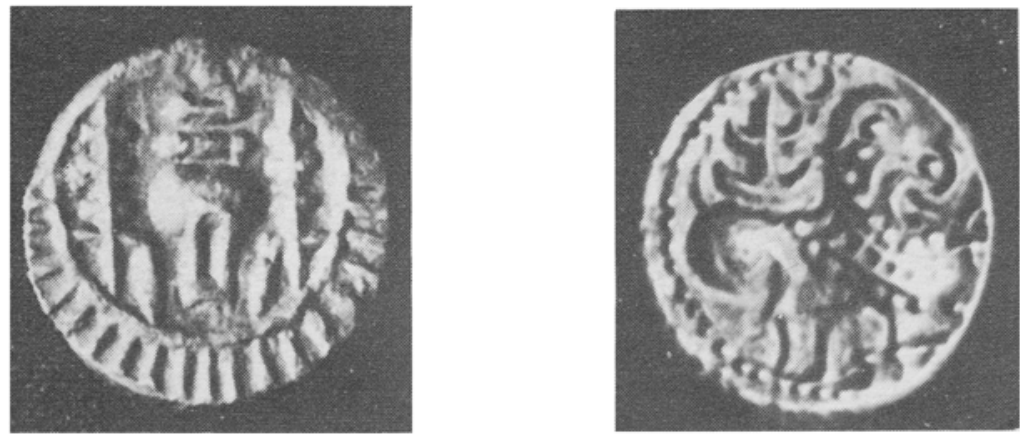

\section{Tangadupalli coins}

Figure 1. Photographs of the BACRI. Kesaragutta and Tangadupalli coins. 
This paper presents the details of our investigation on chemical and microstructural aspects of these coins of the Vishnukundin period.

\section{Experimental}

About $1-5 \mathrm{mg}$ of the coin samples were obtained with the help of microdriller from the rim of each coin after removing the surface incrustations carefully. The samples thus obtained were screened by the use of a medium Hilger-Watts large quartz spectrograph to know the composition qualitatively. The quantitative chemical analyses were carried out using an atomic absorption spectrophotometer (Perkin Elmer 2380).

Microstructural studies were carried out on a cut cross-section of the coins after mounting the pieces in Bakelite, polishing and etching it with ferric chloride. All microchemical studies were done using a scanning electron probe microanalyzer, (Camebax-Micro) equipped with a microprocessor-controlled wavelength dispersive spectrometer system for $\mathrm{x}$-ray analysis.

\section{Results and discussion}

\subsection{Physical measurements}

Table 1 summarizes physical measurements of the Vishnukundin coins. The coins of the BACRI museum are significantly thinner and smaller than the Kesaragutta and Tangadupalli Vishnukundin coins. The average weight of the BACRI coins is about $3.34 \mathrm{~g}$ and the average maximum and minimum diameters, $1.55 \mathrm{~cm}$ and $1.48 \mathrm{~cm}$ respectively. The thickness is not uniform throughout the coin. The average weights

Table 1. Physical measurements data of Vishnukundin copper coins.

\begin{tabular}{cccc}
\hline $\begin{array}{c}\text { Weight } \\
(\mathrm{g})\end{array}$ & $\begin{array}{c}\text { Maximum diameter } \\
(\mathrm{cm})\end{array}$ & $\begin{array}{c}\text { Minimum diameter } \\
(\mathrm{cm})\end{array}$ & $\begin{array}{c}\text { Thickness } \\
(\mathrm{cm})\end{array}$ \\
\hline \multicolumn{3}{c}{ BACRl coins } \\
2.944 & 1.53 & 1.50 & 0.32 \\
3.241 & 1.40 & 1.35 & 0.46 \\
3.024 & 1.50 & 1.50 & 0.31 \\
3.902 & 1.55 & 1.48 & 0.47 \\
3.735 & 1.71 & 1.55 & 0.34 \\
4.175 & 1.53 & 1.48 & 0.57 \\
& \multicolumn{2}{c}{ Kesaragutta coins } \\
6.722 & 2.10 & 2.00 & \\
5.140 & 1.89 & 1.85 & 0.48 \\
6.063 & 2.00 & 1.85 & 0.39 \\
6.010 & 1.87 & 1.81 & 0.41 \\
& \multicolumn{2}{c}{ Tangadupalli coins } & 0.41 \\
6.522 & 2.10 & 2.03 & \\
6.759 & 2.50 & 2.30 & 0.41 \\
6.840 & 2.30 & 2.25 & 0.40 \\
5.851 & 1.98 & 1.97 & 0.48 \\
\hline
\end{tabular}


of Kesaragutta and Tangadupalli coins are about $5.98 \mathrm{~g}$ and $6.49 \mathrm{~g}$ respectively which are heavier compared to the BACRI museum coins. The average maximum and minimum diameters of the Kesaragutta coins are $1.97 \mathrm{~cm}$ and $1.88 \mathrm{~cm}$ respectively and the average thickness is $0.42 \mathrm{~cm}$. For Tangadupalli coins, the average maximum diameters are $2.22 \mathrm{~cm}$ and $2.14 \mathrm{~cm}$ respectively, and the thickness is $0.42 \mathrm{~cm}$. The thickness is almost uniform throughout the coin.

\subsection{Chemical composition}

Table 2 contains the chemical composition of 6 representative coins out of 200 coins of the BACRI museum, along with those of 4 Kesaragutta coins and 4 Tangadupalli coins. Analyses have been carried out to delineate the range of composition for each of the two major, one minor and a few trace elements, i.e. $\mathrm{Cu}, \mathrm{Sn}, \mathrm{Fe}, \mathrm{Co}, \mathrm{Pb}, \mathrm{Ag}, \mathrm{Cr}$.

The material of all the three types of coins was found to be $\mathrm{Cu}-\mathrm{Sn}$ bronze. The $\mathrm{Cu}$ Sn ratio in the coins from three places varied from 2.58 to 3.79 . The analytical values show the presence of tin upto $20-25 \%$. These results were further confirmed by electron probe microanalysis. It appears that the $\mathrm{Cu}: \mathrm{Sn}$ ratio is almost perfectly maintained to mint the bronze coins or the so-called tin money in all coins of three different places of this dynasty. The main object of adding tin to the copper in ancient metallurgy is for work hardening and improved castings (Agarwal 1969; Catling 1977; Scott 1980).

The chemical analysis of Vishnukundin copper coins showed appreciable quantity of iron (table 2). Although iron is present in some coins upto $11.92 \%$, the coins are not attracted by magnet. On the contrary, the analysis of Paunar* coins of the same dynasty was shown to contain iron upto $23 \%$ and are attracted by magnet; it was

Table 2. Chemical composition of Vishnukundin copper coins.

\begin{tabular}{lccccccc}
\hline $\mathrm{Cu} \%$ & $\mathrm{Sn} \%$ & $\mathrm{Fe} \%$ & $\mathrm{Co} \%$ & $\mathrm{~Pb} \%$ & $\mathrm{Ag} \%$ & $\mathrm{Cr} \%$ & $\mathrm{Cu} / \mathrm{Sn}$ \\
\hline 76.22 & 21.02 & 2.18 & - & 0.45 & 0.04 & 0.09 & 3.62 \\
72.73 & 24.53 & 1.46 & 0.26 & 0.50 & - & 0.23 & 2.96 \\
74.13 & 20.67 & 3.33 & 0.33 & 0.50 & 0.04 & 0.25 & 3.59 \\
72.06 & 22.07 & 2.75 & 0.99 & 0.67 & 0.05 & 0.15 & 3.26 \\
77.87 & 20.50 & 0.44 & 0.38 & 0.44 & 0.02 & 0.30 & 3.79 \\
72.02 & 24.73 & 2.47 & 0.13 & 0.21 & 0.02 & 0.08 & 2.91 \\
& & \multicolumn{7}{c}{ Kescraragutta coins } & & & \\
71.57 & 24.17 & 3.68 & 0.02 & 0.18 & 0.02 & 0.01 & 2.96 \\
73.80 & 22.08 & 3.75 & 0.01 & 0.11 & 0.03 & 0.01 & 3.34 \\
71.60 & 24.15 & 4.03 & 0.01 & 0.17 & 0.04 & 0.02 & 2.96 \\
72.50 & 23.99 & 3.13 & 0.02 & 0.15 & 0.02 & 0.01 & 3.02 \\
& & \multicolumn{7}{c}{ Tangadupalli coins } & & & \\
72.56 & 23.07 & 3.98 & 0.10 & 0.12 & 0.03 & 0.02 & 3.15 \\
73.97 & 22.03 & 3.39 & 0.02 & 0.25 & 0.02 & 0.02 & 3.36 \\
73.50 & 21.81 & 5.65 & 0.05 & 0.21 & 0.03 & 0.01 & 3.37 \\
63.25 & 24.56 & 11.92 & 0.08 & 0.18 & 0.02 & 0.02 & 2.58 \\
\hline
\end{tabular}

*Paunar $\left(20^{\circ} \cdot 27^{\prime} \mathrm{N}, 78^{\circ} \cdot 41^{\prime} \mathrm{E}\right)$, a village in the Wardha Taluka of Wardha Dist., Maharashtra, India 
suggested that those coins were alloyed with iron and some contained iron ore (Hegde 1975).

The presence of trace elements (see table 2) associated with the coins of all the places suggests that no elaborate treatment was carried out for refining the metals/ ores.

\subsection{Microstructural studies}

Figures 2 and 3 show the optical micrographs and the $x$-ray elemental distribution maps for the cross-section of a BACRI coin. The cross-section exhibits a threelayered structure. The right side of figure $2 \mathrm{~A}$ shows the completely corroded layer, and the centre, the partially corroded one. The interior region is shown in figure $2 \mathrm{~B}$. The microstructure in figures 2 and 3 clearly reveals a two-phase structure in the interior as well as partially corroded regions. Quantitative electron probe microanalysis indicates the composition of the light etching phase to be $\mathrm{Cu}-15 \mathrm{wt} \% \mathrm{Sn}$, and that of matrix phase to be $\mathrm{Cu}-25 \mathrm{wt} \% \mathrm{Sn}$ in the interior region. The composition of the matrix phase in the outer regions, however, is found to be $28 \mathrm{wt} \% \mathrm{Cu}-51 \mathrm{wt} \%$ $\mathrm{Sn}-3 \mathrm{wt}_{0} \mathrm{Fe}-\mathrm{O}\left(\mathrm{Cu}_{2} \mathrm{O}+2 \mathrm{SnO}_{2}\right)$ thus showing it to be an oxide phase formed probably because of weathering due to bad preservation of the coin. Iron particles containing about $2-8 \mathrm{wt}_{\mathrm{O}}^{\mathrm{n}} \mathrm{Cu}$, appearing as black features in figure $2 \mathrm{~B}$ and white inclusions in the absorbed current image in figure 3 are also seen in the interior region. The microstructure of the inner and the partially corroded layer also shows a few sulphide particles of size $<5 \mu \mathrm{m}$. Its composition in the inner region is Cu$14 \mathrm{wt}_{\circ}^{\circ} \mathrm{Fe}-26 \mathrm{wt}_{\%}^{\circ} \mathrm{S}$, and in the outer region, $\mathrm{Cu}-19 \mathrm{wt}_{\%}^{\mathrm{o}} \mathrm{S}$.

The microstructure of the Tangadupalli coin is shown in figure 4. Figure 4A indicates equiaxed, well-refined grains with a fine dispersion of precipitates in the grains. Iron particles (black features in figure 4B), pure copper regions enveloped by dark green phases (figure 4C) and grey particles (figure 4A) are also seen in the microstructure. The greenish phases appear as big lumps, sometimes as big as $1 \mathrm{~mm}$ in diameter, while grey phases appear as small inclusions throughout the matrix. Microprobe studies indicate that the matrix is $\mathrm{Cu}-25 \mathrm{wt}_{i 0}^{\circ} \mathrm{Sn}$, the dark green phases are copper and tin oxides of uncertain composition, and the grey inclusions are sulphide ore particles having $\mathrm{Cu}-13 \mathrm{wt} \% \mathrm{Fe}-28 \mathrm{wt} \% \mathrm{~S}$. The greenish phase and pure copper regions contain a small amount of iron also. The elemental distribution maps of a region near a dark green feature in figure 5 clearly show the iron particles and sulphide inclusions along with copper and tin rich regions of the greenish phase.

Material-wise, Kesaragutta coin appears to be the same as the Tangadupalli coin but for one major difference in that the microstructures, shown in figure 6, do not indicate any refined grains. Similar to the Tangadupalli coin, the microstructure shows pure copper regions surrounded by dark green phases, iron particulates and sulphide ore inclusions of same composition.

Chemica! and microstructural evidence strongly suggests that the starting materials used are the same for Tangadupalli and Kesaragutta coins. The sulphide particles present have a composition close to that of bornite, $\mathrm{Cu}_{5} \mathrm{FeS}_{4}$, suggesting that bornite ore, available only in the Agnigundala area of Nallakonda, Guntur District (AP) was the source of copper. It was also confirmed by geologists that the minerological zoning (depthwise) was observed in the Nallakonda block and surface sections were rich in bornite followed by chalcopyrite and galena at depth (Rama 

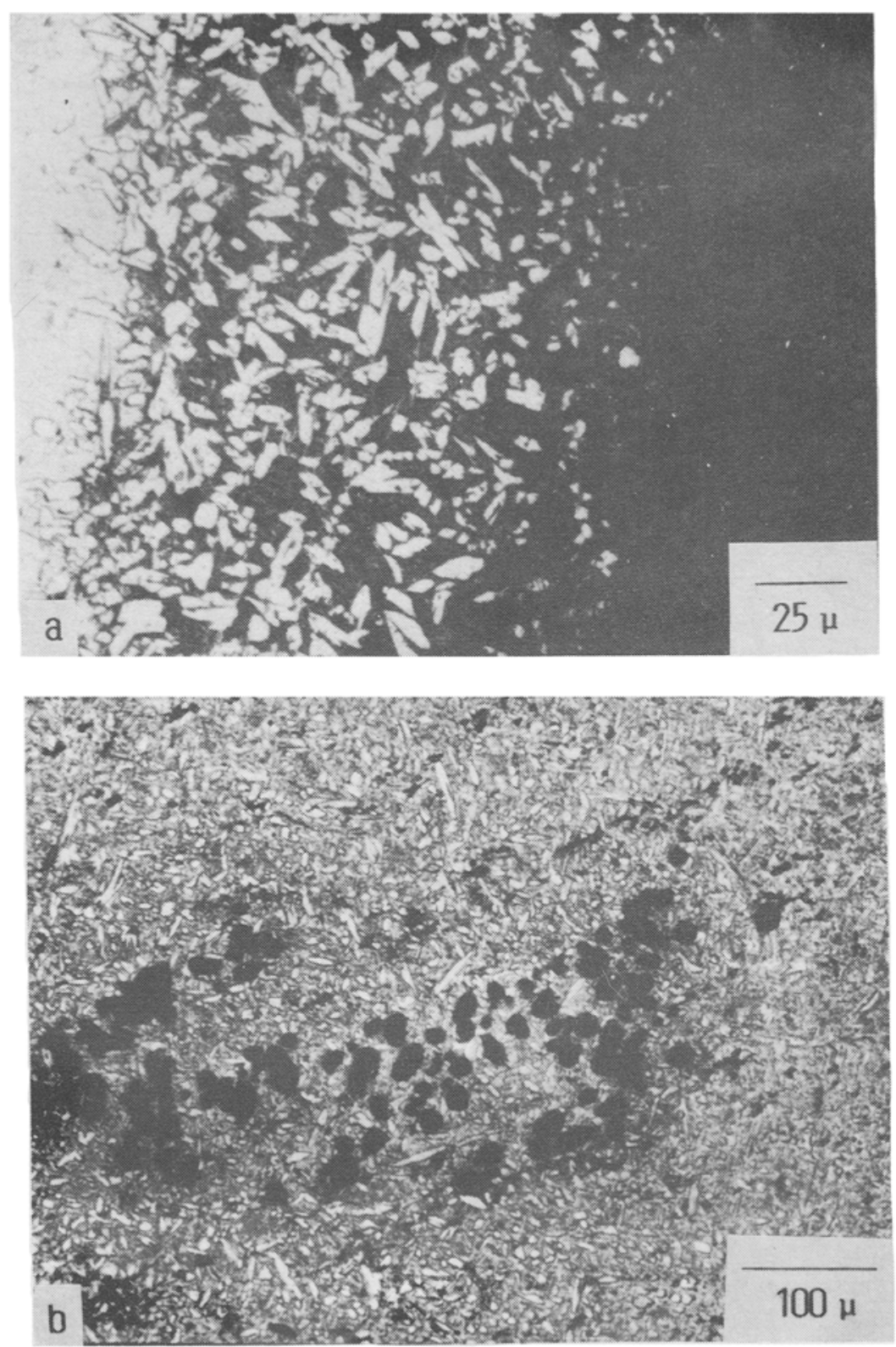

Figure 2. Photomicrographs of a cross-section of BACRI coin.

Rao 1952). The presence of copper-tin-oxide regions indicates that cassiterite, an oxide ore of tin was used as the source of tin. This is so because tin oxide has a melting point of $1630^{\circ} \mathrm{C}$ compared to $231.9^{\circ} \mathrm{C}$ of pure tin, and hence is likely to be left undissolved at the temperatures used for making copper. It is probable that copper and tin ores were intimately mixed, partially oxidized. and then reduced to get the alloy. Such a method is likely to leave copper-tin-oxide regions noticed in the microstructure of both Tangadupalli and Kesaragutta coins. BACRI coin, on the 

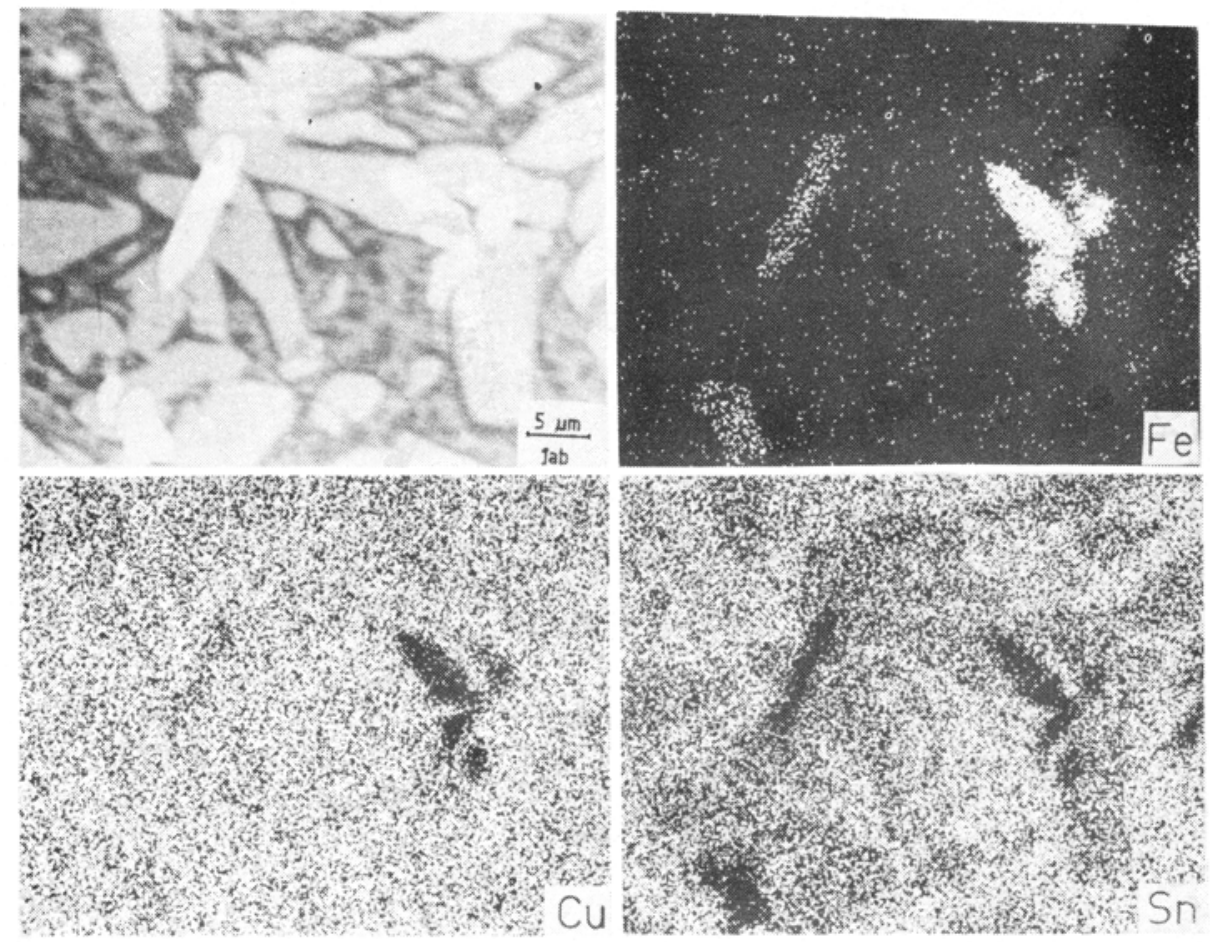

Figure 3. X-ray elemental distribution maps of a BACRI coin.

other hand, does not show any tin oxide particles left in the matrix, indicating that pure tin itself has possibly been used in making the alloy. The difference in the source of raw materials and their processing for Tangadupalli and Kesaragutta coins on the one hand, and BACRI coins on the other are also borne out by the difference in the $\mathrm{Pb}, \mathrm{Co}$ and $\mathrm{Cr}$ content of the coins (see table 2). It is also interesting to note that silica inclusions are not seen in the microstructure. Thus the ores have been processed well to remove all the extraneous material.

The solubility of iron in bronze is very low. So, iron present in the copper ore has precipitated in the matrix. In fact, in many of the copper coins, it is very likely that the total iron present has come only from the copper ore as a consequence of bad melting practice rather than by deliberate addition as has been suggested earlier (Hegde 1975).

Microstructure of the BACRI coin suggests it to be in the as-cast condition. In the partially corroded regions, however, twinning was observed, suggesting that this outer layer has been worked and later annealed. The composition indicates that the light etching alpha phase is present in a matrix of $(\alpha+\delta)$. Tangadupalli coin, however, appears to have been worked and annealed resulting in well-refined grain structure as shown in figure 4A. Annealing in high tin bronze is known to result in the precipitation of $\varepsilon$ phase as a fine dispersion (Reeves et al 1953), and this is also noticed in the microstructure. Micrographs in figure 6 showing the acicular $\alpha$-needles in a matrix of $\delta$-phase indicate a martensitic type of structure produced by water quenching of tin bronze with about $25 \mathrm{wt} \% \mathrm{Sn}$ after annealing at $700-750^{\circ} \mathrm{C}$ i.e. in the $\beta$-region of the 

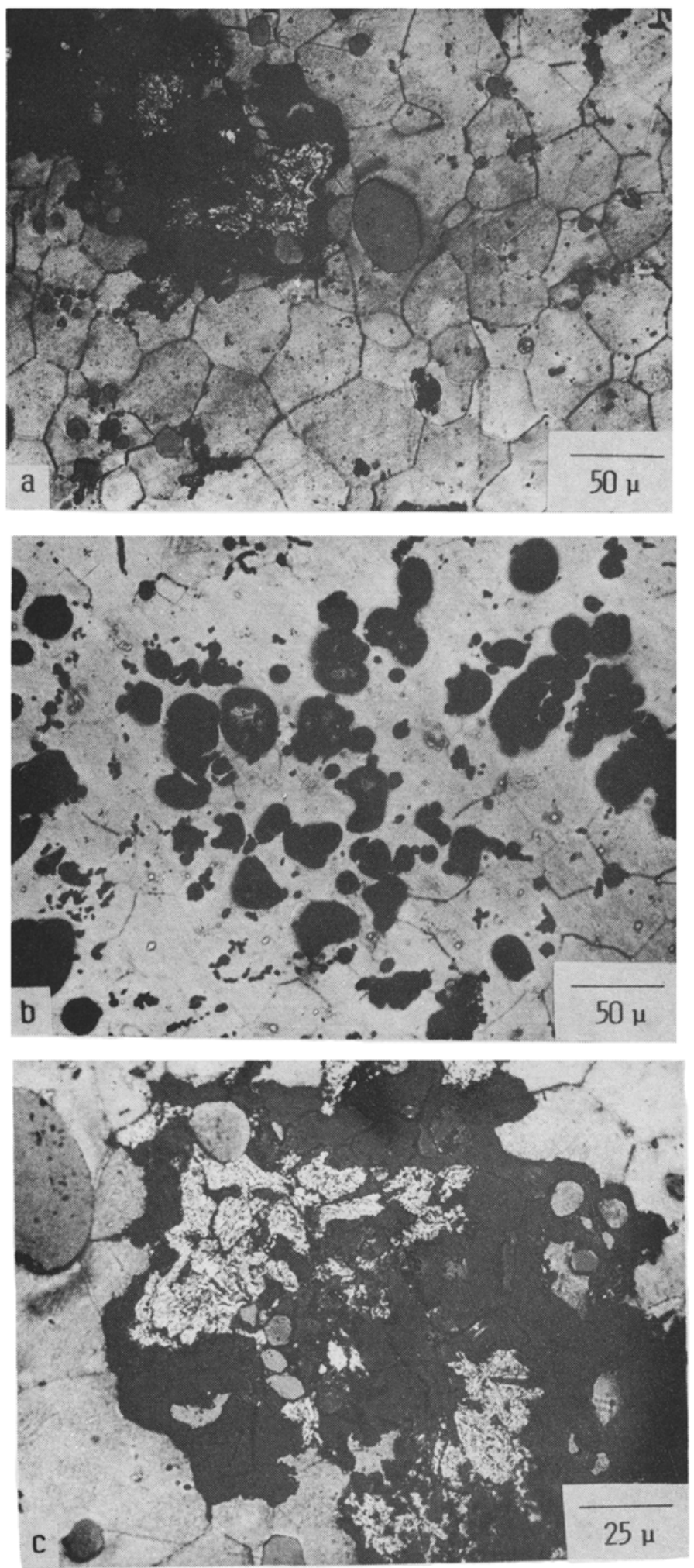

Figure 4. Photomicrographs of a cross-section of a Tangadupalli coin. 


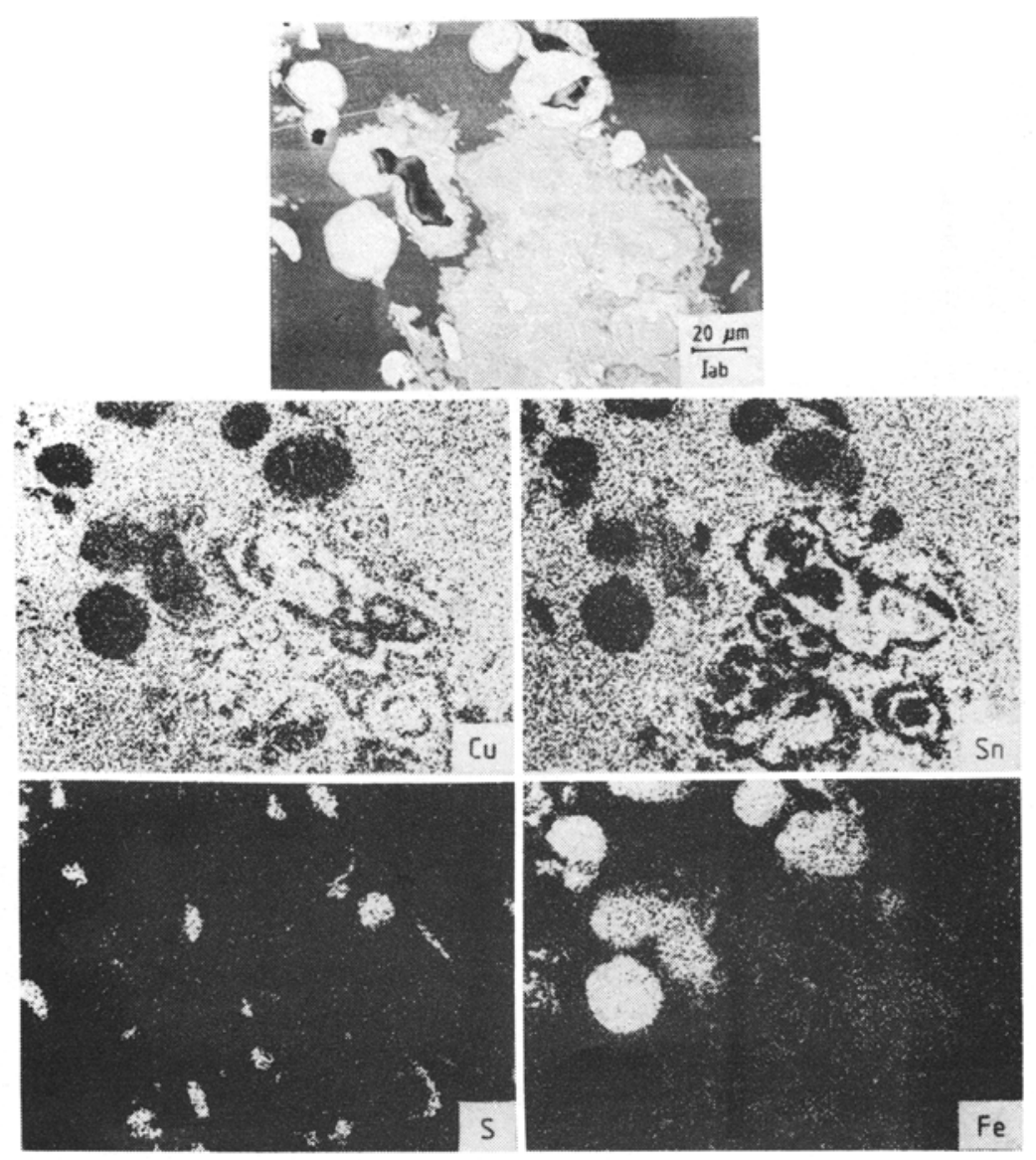

Figure 5. X-ray elemental distribution maps of a Tangadupalli coin.

phase diagram (Reeves et al 1953). This sort of acicularity disappears slowly on tempering resulting in the type of structure shown in figure 4 for the Tangadupalli coin. Soaking in the $\beta$-range and quenching in the case of bronzes containing $>20 \mathrm{wt}^{\circ}{ }_{0}$ Sn helps to soften the alloy (Reeves et al 1953).

In conclusion, it appears that while BACRI coins are made by alloying metallic copper and tin as starting materials, Tangadupalli and Kesaragutta coins are made by direct mixing of the ores of copper and tin and processing them together. In both cases, the presence of sulphide particles of composition close to that of bornite suggests that local copper ores were used. It is not yet clear as to how exactly the coins were fabricated from the alloy melt of high tin containing bronzes which are quite brittle in nature, even though the evidence presented suggests that a certain amount of processing has been done on the alloy to make the coins.

\section{Acknowledgements}

The authors are thankful to Dr V V Krishna Sastry, Director, S Ramakantham. Curator and Dr Mir Fazaluddin Ali Khan, coin keeper of Andhra Pradesh State 

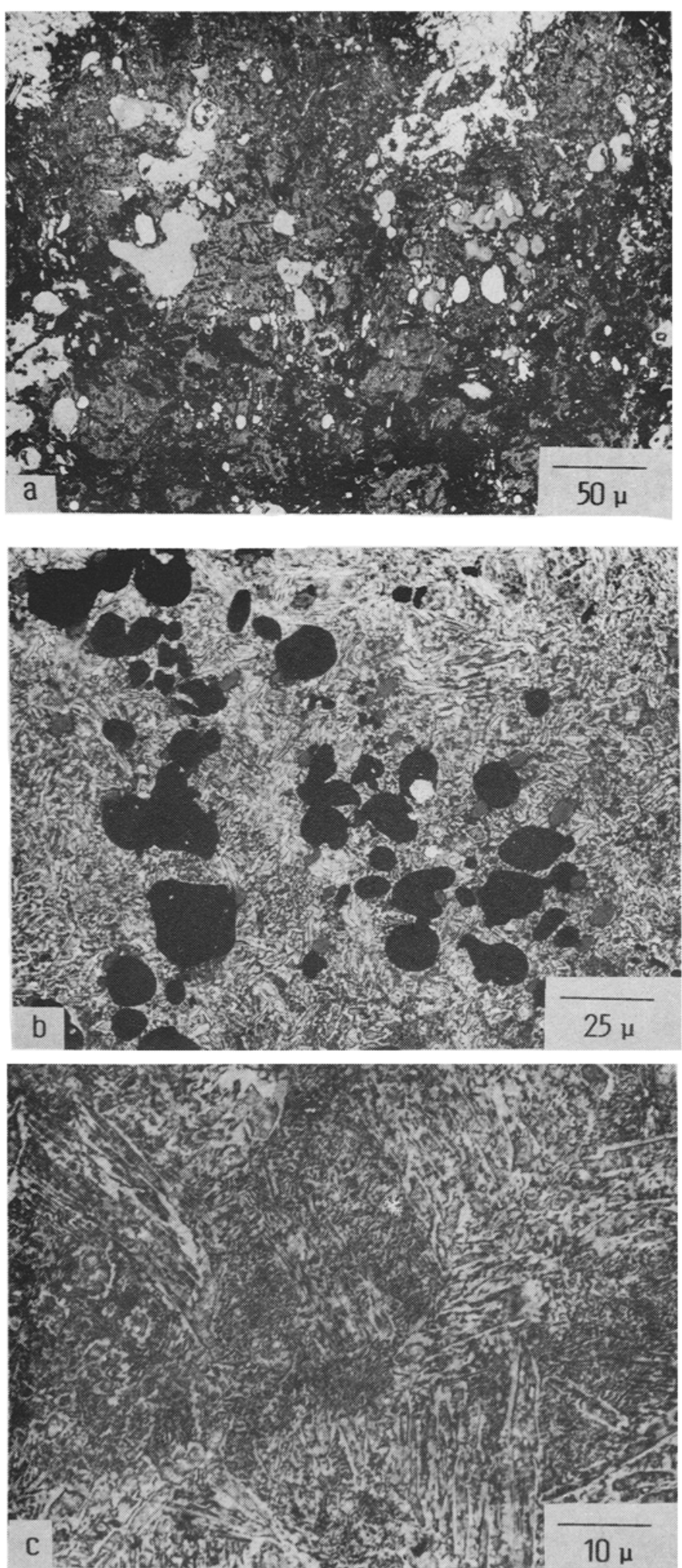

Figure 6. Photomicrographs of a cross-section of a Kesaragutta coin. 
Department of Archaeology and Museums for their kind co-operation in making the samples available for analyses, and for valuable suggestions. The authors are also thankful to Dr B R Rao of Geological Survey of India for permitting us to use the emission spectrograph. We are grateful to the Director, DMRL for providing the facilities to carry out metallurgical studies.

\section{References}

Agarwal D P 1969 The copper bronze age in India, (ed) Md Abdul Waheed Khan (Hyderabad: Department of Archeology) 109-204

Catling H W and Jones R E 1977 Archaeometry 57

Hegde K T M 1975 J. Numis. Soc. India 180

Rama Rao M 1963 AP Govt. Archeol. Ser. 10

Rama Rao K and Appavadhanulu K 1952 Q.J. Geol. Min. Metall. Soc. India 2475

Reeves M R, Bowden J S and Cuthbertson J W 1953 Met. Ind. 8240

Scott D A 1980 Stud. Conserv. 25157. 